\title{
PENERAPAN MODEL COACHING SEBAGAI UPAYA MENINGKATKAN KEPUASAN MASYARAKAT DALAM PELAYANAN KESEHATAN DI POSYANDU LANSIA
}

\author{
Achmad Junaedi ${ }^{1)}$, Titik Suhartini ${ }^{2)}$ \\ ahmatjunaedi2014@gmail.com \\ Prodi DIII Keperawatan, STIKES Hafshawaty Pesantren Zainul Hasan Probolinggo
}

\begin{abstract}
ABSTRAK
Jumlah lanjut usia di Indonesia semakin bertambah dan hal ini membawa pengaruh besar dalam pengelolaan masalah kesehatannya. Kesehatan fisik dan mental merupakan faktor utama dalam peningkatan usia harapan hidup. Untuk menjaga kesehatan fisik dan mental diperlukan upaya pembinaan lansia melalui puskesmas dengan mendirikan posyandu lansia. Tujuan penelitian ini adalah menganalisis penerapan model coaching sebagai upaya meningkatkan kepuasan masyarakat dalam pelayanan kesehatan di posyandu lansia. Penelitian ini menggunakan desain penelitian pra eksperimen dengan metode one-group pretest-posttes design. Populasinya adalah seluruh kader di Desa Sidorejo. Teknik sampling yang digunakan adalah total sampling berjumlah 20 kader dan 60 lansia. Pengumpulan data dengan menggunakan kuesioner. Analisa data dengan paired T Test untuk mengetahui pengaruh antara dua variabel dengan tingkat kemaknaan $p \leq 0,05$. Hasil penelitian diperoleh kepuasan responden sebelum dilakukan penerapan model coaching sebagian besar kurang puas (65\%). Sedangkan kepuasan setelah penerapan model coaching sebagian besar merasakan puas $(86,7 \%)$. Hasil uji analisa data diperoleh kesimpulkan ada pengaruh penerapan model coaching sebagai upaya meningkatkan kepuasan masyarakat dalam pelayanan kesehatan di posyandu lansia. Proses coaching merupakan kegiatan pendampingan yang sangat memberikan pengaruh baik terhadap coachee. Proses yang berkesinambungan dapat memberikan perubahan yang signifikan terhadap bentuk pelayanan kesehatan khususnya yang dilakukan oleh kader kesehatan.
\end{abstract}

Kata kunci : coaching, kepuasan, posyandu lansia

\section{ABSTRACT}

The number of elderly in Indonesia is growing. It has a major impact on the management of health problems. Physical and mental health is a major factor in increasing life expectancy. In maintaining physical and mental health is required effort of coaching elderly group through puskesmas by establishing posyandu for elderly. This research used pre experimental research design with one-group pretest-posttes design method. The population was all cadres in Sidorejo Village. The sampling technique used was total sampling amounted to 20 cadres and 60 elderly. Analysis of data user paired $T$ Test to determine the effect between two variables with significance level $p \leq 0.05$. The result of the research was the satisfaction of respondent before the implementation of coaching model mostly with less satisfied (65\%). While satisfaction after application of coaching model mostly feel satisfied (86,7\%). The results of data analysis test obtained that there was influence of application of "Coaching" model as efforts to improve public satisfaction in health care at posyandu for elderly. The coaching process is an advisory activity that greatly influences both coachee and coachee service suggestions. Continuous processes can provide significant changes to the form of health services especially those conducted by health cadres.

Keywords: coaching, satisfaction, posyandu for elderly 


\section{PENDAHULUAN}

Pos Pelayanan Terpadu (Posyandu) merupakan pusat pelayanan kesehatan yang dikelola dan diselenggarakan untuk dan oleh masyarakat dengan dukungan teknis dari petugas kesehatan dalam rangka pencapaian Norma Keluarga Kecil Bahagia Sejahtera (NKKBS) (Depkes RI, 2013).

Angka kesakitan penduduk lansia tahun 2012 sebesar 26,93\%. Bila dilihat perkembangannya dari tahun 2005-2012, derajat kesehatan penduduk lansia mengalami peningkatan yang ditandai dengan menurunnya angka kesakitan pada lansia. Menurut survey Riskesdas tahun 2006 jumlah lansia 19 juta, dengan usia harapan hidup 66,2 tahun, tahun 2010 jumlah lansia sebanyak 14.439.967 jiwa $(7,18 \%)$ dan pada tahun 2013 meningkat menjadi 35.594.671. Pada tahun 2020 diperkirakan sebesar 28,8 juta $(11,34 \%)$, dengan usia harapan hidup 71,1 (Depkes RI, 2013). Kesehatan fisik dan mental merupakan faktor utama dalam peningkatan usia harapan hidup. Dalam menjaga kesehatan fisik dan mental diperlukan upaya pembinaan kelompok lansia melalui puskesmas dengan mendirikan posyandu lansia. Proses pembinaan dilakukan melalui proses mentoring (coaching).

Coaching dalam supervisi lebih efektif dibanding mentoring dalam supervisi terhadap pengembangan kompetensi klinis, komunikasi dan personal dan profesional (Subramaniam. A, Silong. A, Uli. J \& Ismail. I, 2015). Salah satu upaya untuk meningkatkan mutu pendidikan, salah satunya didukung dengan melakukan program supervisi akademik yang dilandasi coaching (Okprina \& Roesminingsih, 2014). Supervisi klinik dengan pendekatan coaching dapat meningkatkan kualitas pelayanan perawat (Alleyne \& Jumaa, 2007).

Berdasarkan hasil studi pendahuluan di Desa Sidorejo pada tanggal 18 Agustus 2017, yang dilakukan dengan cara wawancara kepada perawat diperoleh data bahwa posyandu lansia sudah dilaksanakan secara aktif sejak 2 tahun yang lalu, pemberian pelayanannya dibantu oleh kader yang ada di Desa Sidorejo yang berjumlah 15 kader. Posyandu lansia dilaksanakan 1 (satu) kali dalam 1 (satu) bulan pada awal bulan. Kader sebagai bagian dari pemberi pelayanan yang membantu tenaga kesehatan sangat berperan penting dalam keaktifan pelaksanaan posyandu lansia.

Peran serta lansia dalam kegiatan posyandu lansia selain dipengaruhi oleh faktor internal dari lansia juga dipengaruhi oleh faktor pemberi pelayanan kesehatan seperti perawat atau bidan dan juga peran serta kader. Pelayanan yang baik akan memberikan nilai kepuasan bagi lansia sehingga lansia bisa lebih berperan aktif dalam kegiatan posyandu lansia. Kader mempunyai peran penting dalam pelaksanaan kegiatan posyandu. Kemampuan dari seorang kader juga akan mempengaruhi cara memberikan pelayanan terhadap masyarakat. Tugas kader yang sangat berhubungan dengan kepuasan layanan kesehatan, menuntut kemampuan yang lebih dari seorang kader. Kegiatan pelatihan ataupun pembekalan seringkali dilakukan untuk meningkatkan pemahaman kader terhadap tugasnya. Metode coaching sangat membantu dalam meningkatkan kemampuan kerja dari kader. Coaching sebagai bentuk kemitraan bersama coachee untuk memaksimalkan potensi pribadi dan professional yang dimilikinya melalui proses yang menstimulasi dan mengeksplorasi pemikiran dan proses kreatif. Tujuan dalam penelitian ini adalah menganalisa penerapan metode coaching sebagai upaya meningkatkan kepuasan masyarakat dalam pelayanan posyandu lansia.

\section{METODE PENELITIAN}

Desain penelitian yang digunakan adalah Pra Eksperimen. Populasinya adalah kader berjumlah 20 responden dan lansia berjumlah 60 responden di Desa Sidorejo. Teknik sampling menggunakan total sampling. Teknik pengumpulan data menggunakan kuesioner. Variabel independen dalam penelitian ini penerapan metode coaching dan variabel dependennya adalah kepuasan masyarakat. Berdasarkan hasil observasi yang telah terkumpul, selanjutnya dilakukan tabulasi dan dianalisis dengan Paired Sample T Test ini untuk mengetahui pengaruh antara dua variabel kategorik dengan tingkat kemaknaan $\mathrm{p} \leq 0,05$. Seluruh pengolahan data statistik dilakukan dengan menggunakan bantuan komputer SPSS. 


\section{HASIL DAN PEMBAHASAN}

Hasil

Data umum dari penelitian ini meliputi karakteristik responden yang terdiri dari usia, jenis kelamin, yaitu sebagai berikut:

Tabel 1. Distribusi Frekuensi Karakteristik Responden (kader), Berdasarkan Usia dan pekerjaan pada kader di Desa Sidorejo Bulan Maret 2018

\begin{tabular}{lrr}
\hline \multicolumn{1}{c}{ Karakteristik } & f & \% \\
\hline Usia (Tahun) & 5 & 25 \\
$20-25$ & 12 & 60 \\
$26-31$ & 3 & 15 \\
$32-37$ & & \\
Pekerjaan & 17 & 85 \\
$\quad$ Ibu Rumah Tangga & 3 & 15 \\
$\quad$ Swasta & &
\end{tabular}

Berdasarkan tabel 1 diperoleh informasi sebagian besar usia 26 - 31 tahun $(60 \%)$ dan pekerjaan sebagian besar ibu rumah tangga $(85 \%)$.

Tabel 2. Distribusi Frekuensi Karakteristik Responden, Berdasarkan Umur, Jenis Kelamin pada lansia di Desa Sidorejo Bulan Maret 2018

\begin{tabular}{ccc}
\hline Karakteristik & f & \% \\
\hline Umur (Tahun) & & \\
$60-74$ & 45 & 75 \\
$75-90$ & 15 & 25 \\
Jenis Kelamin & & \\
Laki-Laki & 47 & 78,3 \\
Perempuan & 13 & 21,7 \\
\hline
\end{tabular}

Sumber: data primer, penelitian 2018

Berdasarkan tabel 2 diperoleh informasi sebagian besar usia 60-74 tahun (75\%) dan jenis kelamin sebagian besar laki-laki $(78,3 \%)$.

Tabel 3. Distribusi frekuensi responden, berdasarkan Kepuasan responden Sebelum Penerapan Metode Coaching di Desa Sidorejo Bulan Maret 2018

\begin{tabular}{lcc}
\hline Kepuasan Responden & f & \% \\
\hline Puas & 21 & 35 \\
Kurang Puas & 39 & 65 \\
Tidak Puas & 0 & 0 \\
\hline Jumlah & 60 & 100 \\
\hline Sumber : data primer, penelitian 2018 &
\end{tabular}

Berdasarkan tabel 3 diperoleh informasi sebagian besar kepuasan sebelum penerapan metode coaching dengan kategori kurang puas $(65 \%)$.

Tabel 4. Distribusi frekuensi responden, berdasarkan berdasarkan Kepuasan responden Sesudah Penerapan Metode Coaching di Desa Sidorejo Bulan Maret 2018

\begin{tabular}{lcc}
\hline Kepuasan Responden & f & \% \\
\hline Puas & 52 & 86,7 \\
Kurang Puas & 8 & 13,3 \\
Tidak Puas & 0 & 0 \\
Jumlah & 60 & 100 \\
\hline Sumber : data primer, penelitian 2018 &
\end{tabular}

Sumber : data primer, penelitian 2018

Berdasarkan tabel 4 diperoleh informasi sebagian besar kepuasan sebelum penerapan metode coaching dengan kategori kurang puas $(65 \%)$.

\section{Analisis Data}

Analisis pengaruh penerapan metode coaching sebagai upaya meningkatkan kepuasan masyarakat dalam pelayanan posyandu lansia tahun 2018

Berdasarkan hasil analisis Paired-Samples T Test didapatkan $\mathrm{P}=0,000$, sehingga $\quad \mathrm{P}=$ $0,000<\alpha=0,05$. Kesimpulan hipotesanya adalah ada pengaruh penerapan metode coaching sebagai upaya meningkatkan kepuasan masyarakat dalam pelayanan posyandu lansia.

\section{Pembahasan}

\section{Kepuasan Responden Sebelum Penerapan Metode Coaching}

Berdasarkan hasil penelitian didapatkan bahwa sebagian besar kepuasan lansia sebelum dilakukan penerapan coaching adalah kurang puas sebanyak 65 responden (75\%).

Kata kepuasan berasal dari bahasa Latin satis, artinya cukup baik atau faction (melakukan atau membuat). Sehingga secara sederhana dapat diartikan sebagai usaha pemenuhan sesuatu. Untuk meningkatkan mutu pelatihan kesehatan tidak ada pilihan lain kecuali peningkatan profesionalisme sumber daya manusia, sebagai modal utama layanan kepada masyarakat, serta berupaya terus menerus melakukan 
berbagai efisiensi dan diferensiasi layanan yang mampu meningkatkan output. Untuk itu pihak pemberi layanan kesehatan dituntut terus mengenali dan merespon berbagai faktor eksternal yang perlu dipertimbangkan.

$$
\text { Menurut Sugiharto }
$$

mendefinisikan kepuasan sebagai tingkat perasaan seseorang setelah membandingkan kinerja atau hasil yang dirasakannya dengan harapannya. Tingkat kepuasan merupakan fungsi dari perbedaan antara kinerja yang dirasakan dengan harapan. Apabila kinerja sesuai harapan, maka pelanggan akan sangat puas. Sedangkan bila kinerja melebihi harapan, maka pelanggan akan merasakan sangat puas. Harapan pelanggan dapat dibentuk oleh pengalaman masa lampau. Pelanggan yang puas akan setia lebih lama, kurang sensitif terhadap harga dan memberi komentar yang baik.

Kepuasan layanan kesehatan dapat terlihat pada kegiatan posyandu yang merupakan pusat pelayanan keluarga berencana dan kesehatan yang dikelola dan diselenggarakan untuk dan oleh masyarakat dengan dukungan teknis dari petugas kesehatan dalam rangka pencapaian Norma Keluarga Kecil Bahagia Sejahtera (NKKBS). Posyandu atau pos pelayanan terpadu, merupakan salah satu bentuk pelayanan kesehatan yang diselenggarakan oleh masyarakat untuk masyarakat dengan dukungan tehnis dari petugas kesehatan.

Pelayanan menjadi ujuang tombak tercapaianya derajat kesehatan masyarakat, khususnya pada lansia yang menjadi sasaran target capaian kesehatan untuk memperpanjang masa lansia. Banyak program kegiatan dibawah naungan puskesmas yang diselenggarakan untuk memberikan jaminan dan fasilitas kesehatan. Pelayan kesehatan tidak hanya dalam bentuk penyediaan fasilitas dan sarana tetapi juga menekankan pada bentuk layanan yang harus diberikan. Hal ini dapat dipengaruhi oleh pemberi layanan kesehatan. Kegiatan posyandu lansia melibatkan peran serta dari kader kesehatan untuk membantu memberikan pelayanan secara maksimal. Baik tidaknya pelayanan yang diberikan oleh kader kesehatan akan memberikan kepuasan yang berbeda kepada lansia.

\section{Kepuasan Responden Sesudah Penerapan Metode Coaching}

Berdasarkan hasil penelitian setelah dilakukan metode coaching diperoleh sebagian besar kepuasan lansia mengatakan puas sebanyak 52 responden $(86,7 \%)$.

Coaching Bermanfaat Bagi

Peningkatan Kinerja. Faktor-faktor yang membuat coaching sangat diperlukan dalam meningkatkan kinerja, antara lain: Perubahan yang cepat pada lingkungan kerja secara lokal dan global yang memiliki dampak secara langsung dengan kinerja, Perubahan organisasi, downsizing, restructuring, mergers dan bertumbuhnya organisasi baru dari luar (pasar bebas), yang membuat pendekatan manajemen tradisional harus diubah menjadi pendekatan modern, Pendekatan pool of talent yang lambat dan kesulitan dalam menarik dan mempertahankan top talent, sehingga pelayanan kesehatan harus berkomitmen dalam pengembangan individu. Kompetisi top talent dari berbagai tempat pelayanan kesehatan lain yang tanpa batas, Terdapat celah yang luas antara apa yang telah dilatih sebelumnya pada supervisor up, dengan kenyataan dinamika pertumbuhan mutu pelayanan kesehatan yang menuntut para pimpinan untuk meningkatkan performa kerja yang lebih baik untuk dapat berkompetisi, Terdapat kegelisahan dari sebagian besar perawat dan pemimpin organisasi yang bergelut dengan kekhawatiran job insecurity, dan tekanan yang meningkat untuk terusmenerus menumbuhkan performa kerja, Adanya gap generation, sehingga diperlukan kemampuan pemimpin untuk berkolaborasi dengan generasi yang berbeda, sehingga mereka merasa dikembangkan dan diperhatikan. Hal ini akan meminimalkan adanya turn over pekerja (Pramudianto, 2015).

Untuk meningkatkan mutu pelatihan kesehatan tidak ada pilihan lain kecuali peningkatan profesionalisme sumber daya manusia, sebagai modal utama layanan kepada masyarakat, serta berupaya terus menerus melakukan berbagai efisiensi dan diferensiasi layanan yang mampu meningkatkan output. Untuk itu pihak pemberi layanan kesehatan dituntut terus mengenali dan merespon 
berbagai faktor eksternal yang perlu dipertimbangkan.

$$
\text { Menurut Sugiharto }
$$

mendefinisikan kepuasan sebagai tingkat perasaan seseorang setelah membandingkan kinerja atau hasil yang dirasakannya dengan harapannya. Tingkat kepuasan merupakan fungsi dari perbedaan antara kinerja yang dirasakan dengan harapan. Apabila kinerja sesuai harapan, maka pelanggan akan sangat puas. Sedangkan bila kinerja melebihi harapan, maka pelanggan akan merasakan sangat puas. Harapan pelanggan dapat dibentuk oleh pengalaman masa lampau. Pelanggan yang puas akan setia lebih lama, kurang sensitif terhadap harga dan memberi komentar yang baik.

Pelanggan dalam hal ini adalah lansia membutuhkan pelayanan yang baik dari para pemberi pelayanan (kader kesehatan). Pemberi pelayanan kesehatan dalam hal ini adalah kader kesehatan, memberikan dampak yang luar biasa terhadap penerimaan pelayanan bagi lansia. Kegiatan pendampingan metode coaching memberikan hasil yang baik dalam pemberian pelayanan kesehatan. Di dalam pelaksanaannya lebih menekankan pada pemberian pelayanan yang berbasis humanistik dan memahami masing-masing kebutuhan lansia.

\section{Analisis Pengaruh Penerapan Metode Coaching sebagai Upaya Meningkatkan Kepuasan Masyarakat dalam Pelayanan Posyandu Lansia Tahun 2018}

Berdasarkan hasil analisis PairedSamples $\mathrm{T}$ Test didapatkan $\mathrm{P}=0,000$, sehingga $P=0,000<\alpha=0,05$. Kesimpulan hipotesanya adalah, ada pengaruh penerapan metode coaching sebagai upaya meningkatkan kepuasan masyarakat dalam pelayanan posyandu lansia tahun 2018 .

Coaching sebagai bentuk kemitraan bersama coachee untuk memaksimalkan potensi pribadi dan professional yang dimilikinya melalui proses yang menstimulasi dan mengeksplorasi pemikiran dan proses kreatif. Coaching ditekankan pada 3 (tiga) hal: kemitraan, pemberdayaan dan optimalisasi. Kesetaraan ini berarti tidak ada pihak yang otoritasnya lebih tinggi. Berdasarkan prinsip kemitraan dan kesetaraan, maka coaching berfokus pada tujuan dan mendukung coachee agar dapat mencapai hasil yang lebih baik dibandingkan coachee yang melakukan proses eksplorasi sendiri, Pemberdayaan, inilah yang membedakan coaching dengan jenis pengembangan pribadi lainnya. Proses memberdayakan pikiran berbeda dengan instruksi, mengarahkan, atau perintah satu arah saja. Memberdayakan pikiran cenderung dalam bentuk dialog, diskusi atau tanya jawab antara seorang coach dan coahee yang memancing/merangsang proses berfikir mendalam pada diri coachee tersebut. Dari proses memberdayakan pikiran tersebut akan mampu menggali inspirasi coachee menemukan jawabanjawaban sendiri yang mungkin mereka tidak sadar sebelumnya, Optimalisasi. Peran seorang coach bukan hanya memastikan coachee menemukan jawaban dari masalah atau tantangannya, dan juga memastikan bagaimana jawaban tersebut diterapkan oleh coachee dalam bentuk tindakan-tindakan nyata yang pada akhirnya mampu mengoptimalkan potensi pribadi atau profesional mereka, bergantung dalam konteks apa proses coaching itu sedang dilakukan (Pramudianto, 2015).

Kegiatan pendampingan yang dilakukan secara intensif kepada kader dapat menambah kemampuan kader dalam memberikan pelayanan kesehatan kepada lansia. Kader lebih caring atau peduli dengan lansia, peka terhadap kebutuhan dan keluhan lansia, lebih sabar dalam memberikan pelayanan. Sikap tersebut dapat memberikan perubahan respon kepuasan dari lansia. Dampak lainnya adalah lansia lebih aktif mengikuti kegitan posyandu lansia karena mendapatkan pelayanan yang baik dari kader dan petugas kesehatan.

\section{KESIMPULAN DAN SARAN}

\section{Kesimpulan}

Kepuasan masyarakat tentang pelayanan posyandu lansia sebelum dilakukan coaching sebagian besar kurang puas. Kepuasan masyarakat tentang pelayanan posyandu lansia sesudah dilakukan coaching sebagian besar puas. Ada pengaruh penerapan metode coaching terhadap kepuasan masyarakat tentang pelayanan posyandu lansia. 


\section{Saran}

Kepuasan dalam pelayanan kesehatan tidak hanya dipengaruhi oleh tersedianya fasilitas dan sarana kesehatan, tetapi juga dipengaruhi oleh pemberi pelayanan kesehatan. Kemampuan dalam memberikan pelayanan kesehatan memerlukan kemampuan terutama dalam melatih diri untuk bersikap menghargai dan peka terhadap kebutuhan masyarakat. Apalagi yang menjadi sasaran layanan kesehatannya adalah lansia, yang mempunya keterbatasan secara fisik dan mengalami penurunan fungsi kesehatan karena faktor usia. Metode coaching yang dilakukan kepada pemberi pelayanan kesehatan, mampu memberikan perubahan terhadap layanan kesehatan terutama dalam kegiatan posyandu lansia.

\section{REFERENSI}

Alleyne J, Jumaa MO. (2007). Building the capacity for evidence-based clinical nursing leadership: the role of executive co-coaching and group clinical supervision for quality patient services. $J$ Nurs Manag. Mar;15(2):230-243, diakses tanggal 07 Agustus 2017.
Depkes. RI. (2013). Profil Kesehatan Indonesia, JNPK - FR, Jakarta.

Okprina DM, Roesminingsih E. (2015). Strategi Komunikasi Pengawas Pendidikan Menengah Di Lingkup Dinas Pendidikan Kabupaten Gresik. Jurnal Inspirasi Pendidikan, 4(4):108-121, diakses tanggal 07 Agustus 2017.

Pramudianto. (2015). I'm Coach. CV Andi Offset, Yogyakarta.

Sugiharto. AS. (2012). Manajemen Keperawatan, Aplikasi MPKP, EGC, Jakarta.

Subramaniam A, Silong A, ULi J, Ismail I. (2015). Effects of coaching supervision, mentoring supervision and abusive supervision on talent development among trainee doctors in public hospitals, moderating role of clinical learning environment. BMC Med Educ:;15:129, diakses tanggal 07 Agustus 2017 